\title{
Breast cancer, pregnancy, and the pill
}

\author{
JAMES OWEN DRIFE
}

There is still no satisfactory explanation for the effect of pregnancy on the risk of breast cancer. Breast cancer is commoner among women who have never borne children than among parous women, and the longer a woman delays her first pregnancy the more she increases her risk of developing the disease. ${ }^{12}$ Recently it has been suggested ${ }^{3}$ that prolonged use of oral contraceptives before first full-term pregnancy may increase the risk of breast cancer, although after this pregnancy the risk is probably unaffected by taking the pill.

Clearly the first full-term pregnancy does something to alter a woman's risk of developing breast cancer. Before this pregnancy the breast is at greater risk of precancerous change: afterwards the risk diminishes. Whether or not a woman breast-feeds is probably irrelevant ${ }^{4}$ : so far as the breast is concerned the important thing is that a full-term pregnancy has occurred. There are three possible explanations for this. One is that a woman's hormonal state is permanently altered by her first pregnancy. This has been investigated but no consistent answer has emerged. ${ }^{5}$ A second possibility is that during the first pregnancy cells that have undergone precancerous change are destroyed, immunologically or otherwise. There is no evidence that this occurs, and indeed since pregnancy is a period of increased immunological tolerance such a phenomenon seems unlikely. The third explanation is that the breast epithelium itself is permanently changed by pregnancy. There is good evidence that such a change occurs.

\section{Effect of parity on the breast}

Early in pregnancy little change occurs in the breast lobules, but during the second trimester they undergo proliferation.? After pregnancy (or at the end of breast-feeding) involution occurs, until the histological structure of the breast is similar to that of a nulliparous woman's breast. Recently, however, it has been shown $^{8}$ that the epithelium of the ductules remains slightly but importantly altered: "clear" cells are less numerous after first pregnancy than in the ductules of nulliparous women. More striking than this histological change, however, is the physiological change in the epithelium, shown by its altered response to hormones.

Synthesis of DNA in vitro by specimens of normal breast tissue from parous women shows a clear cyclical pattern according to the day of the menstrual cycle on which tissue was obtained $^{9}$ (fig). Synthesis is maximum during the luteal phase of the cycle and increases rapidly with the appearance of progesterone in the circulation. By contrast, among nulliparous women no cyclical pattern is seen. In another study ${ }^{10}$ in-vitro synthesis of

\footnotetext{
University Department of Obstetrics and Gynaecology, Bristol Maternity Hospital, Bristol BS2 8EG

JAMES OWEN DRIFE, BSC, MRCOG, lecturer
}

immunoglobulins showed a similar phenomenon: among parous women there was a pronounced increase in $\operatorname{IgA}$ synthesis during the luteal phase of the cycle, but among nulliparous women no cyclical changes occurred.

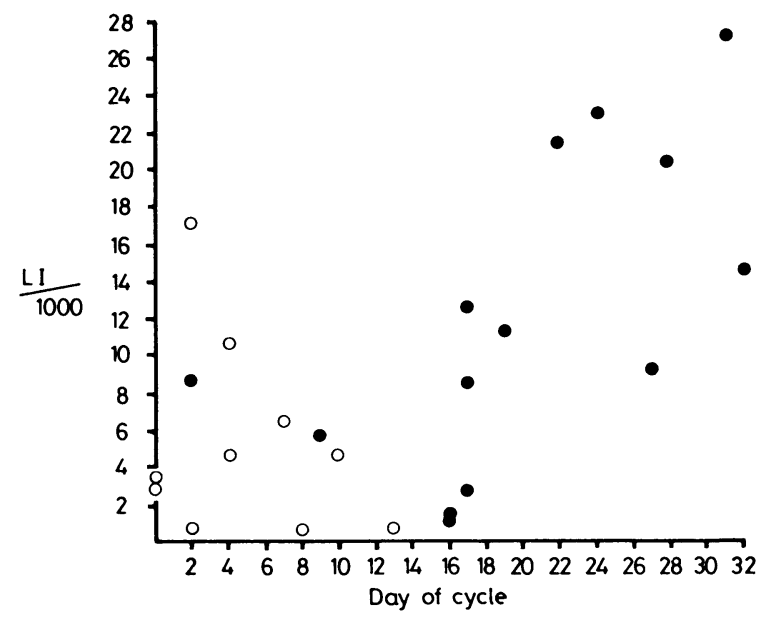

In-vitro DNA synthesis by normal breast tissue from parous women: relationship between epithelial cell labelling indices and day of cycle. $O$ denotes specimens from women with a plasma progesterone concentration under $1 \mathrm{ng} / \mathrm{ml}$; denotes those where concentration was over $1 \mathrm{ng} / \mathrm{ml}$, signifying presence of a corpus luteum. (From Masters et $a l^{9}$ with permission.)

In both these studies the plasma concentrations of progesterone and oestrogen were similar in nulliparous and parous women. The difference between these two groups of women lay not in the state of their hormones but in the ability of the breast tissue to respond to these endogenous hormones. That is to say, pregnancy permanently altered the hormone responsiveness of the epithelium. How this effect is brought about is not clear: possibly the high progesterone concentrations of late pregnancy induce progesterone receptors. We can conclude, however, that after a single full-term pregnancy the breast epithelium becomes capable of responding to circulating progesterone at the relatively low concentrations present during the normal menstrual cycle. Until the first full-term pregnancy has occurred, it cannot respond to progesterone at these concentrations.

\section{Carcinogenesis and the pill}

Exposure to oestrogen "unopposed" by progesterone is now recognised as a carcinogenic influence on the endometrium.11 In recent years regimens of so-called "hormone replacement therapy" for postmenopausal women have been altered by adding a progestogen in the hope that this will prevent the de- 
velopment of endometrial carcinoma. ${ }^{12}$ The incidence of breast cancer has also increased among women receiving prolonged treatment with unopposed oestrogen, ${ }^{13}$ and so it is possibleto put it no more strongly - that unopposed oestrogen has a similar carcinogenic effect on the breast. ${ }^{14}$

The importance of an inadequate response to progesterone now becomes clear. If before first pregnancy the breast has inadequate progesterone receptors and cannot respond to endogenous progesterone, then during the normal cycle it will in effect be exposed to "unopposed" oestrogen-despite the presence of normal concentrations of progesterone in the circulation. Therefore it does not matter whether a young woman has ovulatory cycles before her first pregnancy, because even if progesterone is present it will be unable to modify the effect of her endogenous oestrogen. By contrast, after her first pregnancy the incidence of anovulatory cycles matters a great deal, ${ }^{15-17}$ since progesterone, if present, will now be capable of "opposing" the effect of oestrogen.

How does this hypothesis affect the risk to women who take oral contraceptives? Firstly, it implies that the effects of the pill may be different among nulliparous and parous women-as is now being suggested by epidemiological surveys. ${ }^{31 \times 19}$ The combined oral contraceptive provides oestrogen balanced by progestogen, but if the breast of the nulliparous woman cannot respond to the progestogen component, then a young girl taking an oral contraceptive is effectively exposing her breast epithelium to "unopposed" oestrogen. On the other hand, by taking the pill she is suppressing the production of oestrogen by her own ovaries. What we need to know is whether exposure to exogenous oestrogen at the steady low concentration provided by the pill is any more dangerous than endogenous oestrogen at the higher fluctuating concentrations supplied by the ovary. This question has not yet been answered.

The hypothesis summarised here explains the importance of nulliparity and delayed first pregnancy as risk factors for subsequent breast cancer. It also explains the importance of early menarche," :" since the sooner the menstrual cycles begin the sooner the "unopposed" oestrogen begins to act on the breast epithelium. (The importance of a late menopause is explained by the fact that late in a woman's reproductive life her cycles are mainly anovular,"1 and so a woman with a late menopause experiences more oestrogen-only cycles, although her breast epithelium could respond to progesterone if it were present.) The hypothesis could perhaps also explain the recent unconfirmed observation ${ }^{3}$ that an early miscarriage before first fullterm pregnancy is another risk factor: concentrations of both oestrogen and progesterone increase in early pregnancy, but in the nulliparous woman only the oestrogen will affect the breast.

The hypothesis does not attempt to explain the racial and geographical variations in the incidence of breast cancer. ${ }^{22}$ Nor does it offer an opinion on whether one particular oestrogen (such as oestradiol ${ }^{23}$ or oestrone ${ }^{24}$ ) is less carcinogenic than another. What seems clear above all is that future study should concentrate less on women's hormonal profiles and more on the effects of the hormones on the breast itself.

This hypothesis is based on work done while I was an MRC clinical research fellow at the MRC Unit of Reproductive Biology, Edinburgh.

\section{References}

' MacMahon B, Cole P, Lin TM, et al. Age at first birth and breast cancer risk. Bull WHO $1970 ; 43: 209-21$.

2 Shapiro S, Goldberg J, Venet L, Strax P. Risk factors in breast cancer-a prospective study. In: Doll R, Vodopija I, eds. Host environment interactions in the etiology of cancer in man. Lyons: International Agency for Research in Cancer, 1973:169-82.

" Pike MC, Henderson BE, Casagrande JT, Rosario I, Gray GE. Oral contraceptive use and early abortion as risk factors for breast cancer in young women. Br f Cancer 1981 ;43:72-6.

' Kalache A, Vessey MP, McPherson K. Lactation and breast cancer. $\mathrm{Br}$ Med F $1980 ; 280: 223-4$.

5 Kirschner MA. The role of hormones in the etiology of human breast cancer. Cancer 1977;39:2716-26.
${ }^{6}$ Korenman SG. The endocrinology of breast cancer. Cancer 1980;46: 874-8.

${ }^{7}$ Dawson EK. A histological study of the normal mamma in relation to tumour growth: II. The mature gland in pregnancy and lactation. Edinburgh Medical fournal 1935;42:569-98.

${ }^{8}$ Drife JO. Evolution, menstruation and breast cancer. In: Bulbrook RD, Taylor DJ, eds. Commentaries on research in breast disease. Vol 1. New York: Alan R Liss, 1979.

${ }^{9}$ Masters JRW, Drife JO, Scarisbrick JJ. Cyclic variation of DNA synthesis in human breast epithelium. F Natl Cancer Inst 1977;58:1263-5.

10 Drife JO, McClelland DBL, Pryde A, Roberts MM, Smith II. Immunoglobulin synthesis in the "resting" breast. Br Med f 1976;ii:503-6.

11 Thomas DB. Role of exogenous hormones in altering the risk of benign and malignant neoplasms in humans. Cancer Res 1978;38:3991-4000.

12 Paterson MEL, Wade-Evans T, Sturdee DW, Thom MH, Studd JWW. Endometrial disease after treatment with oestrogens and progestogens in the climacteric. Br Med f 1980;280:822-4.

${ }^{13}$ Hoover R, Gray LA, Cole P, MacMahon B. Menopausal estrogens and breast cancer. N Engl f Med 1976;295:401-5.

14 Cole P. Major aspects of the epidemiology of breast cancer. Cancer 1980; $46: 865-7$.

15 Grattarola R. The premenstrual endometrial pattern of women with breast cancer. Cancer 1964;17:1119-22.

${ }^{16}$ Sherman BM, Korenman SG. Inadequate corpus luteum function: a pathophysiological interpretation of human breast cancer epidemiology. Cancer 1974 ;33:1306-12.

${ }^{17}$ Korenman SG. Oestrogen window hypothesis of the aetiology of breast cancer. Lancet $1980 ; \mathrm{i}: 700-1$.

${ }^{18}$ Royal College of General Practitioners. Breast cancer and oral contraceptives: findings in Royal College of General Practitioners' study. $\mathrm{Br} \mathrm{Med}$ f 1981 ;282:2089-93.

19 Vessey MP, McPherson K, Doll R. Breast cancer and oral contraceptives: findings in Oxford-Family Planning Association contraceptive study. Br Med f $1981 ; 282: 2093-4$.

${ }^{20}$ Staszewski J. Age at menarche and breast cancer. $\mathcal{F}$ Natl Cancer Inst $1971 ; 47: 935-40$.

${ }^{21}$ Wallace RB, Sherman BM, Bean JA, Leeper JP, Treloar AE. Menstrual cycle patterns and breast cancer risk factors. Cancer Res 1978;38: 4021-4.

${ }^{22}$ Doll $\mathrm{R}$. The epidemiology of cancers of the breast and reproductive system. Scott Med f 1975;20:305-15.

23 Trichopoulos D, MacMahon B, Brown J. Socioeconomic status, urine oestrogens, and breast cancer risk. I Natl Cancer Inst 1980;64:753-5.

24 Siiteri PK, Schwarz BE, MacDonald PC. Estrogen receptors and the estrone hypothesis in relation to endometrial and breast cancer. Gynecol Oncol $1974 ; 2: 228-38$.

(Accepted 15 fuly 1981)

Does endometriosis occur more often in sterilised than in unsterilised women?

Endometriosis after salpingectomy or tubal sterilisation was first reported in $1930 .^{1}$ This has recently been confirmed ${ }^{2}$; the condition may also occur after tubal coagulation and may begin within a few months of operation. The endometriosis may be painful ${ }^{2}$ and may spread several centimetres from the tubal stump. ${ }^{1}$ The original recommendation for its prevention after salpingectomy was that hysterectomy should be performed in preference whenever possible, ${ }^{1}$ but now it is thought that excision of a wedge of tubal uterine cornu is sufficient. ${ }^{2}$ It is not clear, however, how to prevent its occurrence after other forms of tubal occlusion. The frequency of the condition after tubal sterilisation is unknown. In one study, ${ }^{3}$ fistula formation with endometriosis was found in six out of 20 patients with failed sterilisation, and so a search was made for the condition among patients with successful sterilisation: microscopic evidence of endometriosis was found in $63^{\circ} \%$ of patients with successful tubal cautery but in only $28^{\circ}$ of patients with successful Pomeroy sterilisation. The process occurs within one to four years of operation, and the incidence is lower if the proximal tubal stump measures over $4 \mathrm{~cm}$. It must be emphasised that in this study ${ }^{3}$ endometriosis was specifically sought and was mainly microscopic. The risk of painful clinical endometriosis to a woman undergoing laparoscopic sterilisation with clips or rings is unknown, but must be very low indeed.

' Sampson JA. Postsalpingectomy endometriosis (endosalpingiosis). Am $\mathcal{f}$ Obstet

Gynecol 1930;20:443-80.
Ranney B. Etiology, prevention and inhibition of endometriosis. Clin Obstet

- Rock JA, Parmley TH, King TM, Laufe LE, Su BC. Endometriosis and the development of tuboperitoneal fistulas after tubal ligation. Fertil Steril $1981 ; 35$ : 16-20. 